\title{
A novel glycyrrhetinic acid-modified oxaliplatin liposome for liver-targeting and in vitro/vivo evaluation
}

Jingde Chen*

Hong Jiang*

Yin Wu

Yandong Li

Yong Gao

Department of Oncology and Hematology, East Hospital, Tongji University School of Medicine, Shanghai, People's Republic of China

*These authors contributed equally to this work
Correspondence: Yong Gao Department of Oncology and Hematology, East Hospital, Tongji University School of Medicine, I 50 Jimo Road, Shanghai, People's Republic of China

Email gaoyon@hotmail.com
This article was published in the following Dove Press journal:

Drug Design, Development and Therapy

20 April 2015

Number of times this article has been viewed

Abstract: In this study, oxaliplatin (OX) liposomes surface-modified with glycyrrhetinic acid (GA) were developed by the film-dispersion method. Their morphology, physical and chemical properties, and in vitro release performance were investigated. The transmission electron microscope (TEM) image showed that most liposomes were spherical particles with similar size and uniform dispersion. Both OX-liposomes and GA-OX-liposomes had an average size of $90 \mathrm{~nm}$. They were negatively charged, with zeta potentials of -20.6 and $-21.3 \mathrm{mV}$, respectively, and the entrapment efficiency values of both were higher than $94 \%$. In vitro data showed that the application of liposomes could prolong the OX release. The relatively high correlation coefficient values obtained from analyzing the amount of drug released versus the square root of time depicted that release followed the Weibull model. No significant changes were observed after the addition of GA to the liposomes. In vivo, the relatively long time to reach the maximum plasma concentration of OX-liposomes suggested a sustained-release profile of liposomes, which was consistent with the results of the in vitro release study. The increased area under the curve and maximum plasma concentration of OX-liposomes and GA-OX-liposomes demonstrated an increased absorption. The drug concentration in tissues indicated that the GAmodified liposomes delivered OX mainly to liver after intravenous administration. In addition, no severe signs, such as appearance of epithelial necrosis or sloughing of epithelial cells, were detected in histology studies.

Keywords: target, drug delivery, modified liposomes, pharmacokinetics, biodistribution

\section{Introduction}

Hepatocellular carcinoma (HCC), the fifth most common cancer worldwide and rarely detected at an early stage, is usually fatal within months of diagnosis, resulting in 500,000 deaths per year. ${ }^{1,2}$ It frequently occurs in the setting of chronic liver disease (hepatitis B or $\mathrm{C}$ virus-related) and cirrhosis, and Child-Pugh functional status dictates the chances of treatment. ${ }^{3}$ Despite introduction of potentially curative treatments, such as liver resection and orthotopic liver transplantation, the prognosis is generally poor, as only $10 \%-37 \%$ of patients are suitable surgical candidates because of advanced tumor or poor hepatic functional reserve. ${ }^{4}$ Thus, chemotherapy is chosen to be the first-line treatment for advanced cancer patients, despite the fact that HCC is a relatively resistant tumor, with response rates ranging from $0 \%$ to $29 \%$ in randomized controlled trials. ${ }^{5}$

Oxaliplatin $(\mathrm{OX})$ is one of the third generation of platinum-based anticancer agents and displays a wide spectrum of in vitro cytotoxic and in vivo antitumor activities. ${ }^{6-8}$ As an alkylating agent that causes DNA damage, OX plays an important role in 
combination therapy for HCC. In many clinical studies, $\mathrm{OX}$ has been shown to present activity against advanced or metastatic HCC. ${ }^{9}$ Although $\mathrm{OX}$ has been proven to be associated with a lower level of adverse reaction than cisplatin and carboplatin, it still has the toxicity common to all platinum-based drugs, which seriously limits its clinical application. ${ }^{10,11}$ Consequently, targeting carriers for such agents have attracted increasing attention as efficient drug delivery systems that increase efficacy and lower systemic side effects.

The liposome was one of the first nanomolecular drug delivery systems to show increased delivery of smallmolecular-weight anticancer drugs to solid tumors, by altering the biodistribution of the associated drug. That being the case, liposomes have caught intensive attention during the past 30 years, which has led to the approval of several liposomal drugs for clinical application evaluation. ${ }^{12-14}$ The application of liposomes can, not only increase accumulation of drug within the tumor sites but also, reduce the amount of drug that can penetrate healthy tissues and, thereby, lessen systemic toxicity. Due to the aforementioned merits of liposomes, repeated studies have focused on utilizing liposomes for the targeted delivery of OX, with cases in point including polyethylene glycol (PEG)-liposome ${ }^{15}$ and cationic liposome. ${ }^{16}$

Glycyrrhetinic acid (GA) is a hydrolysis product of glycyrrhizin. Both of these are the main compounds of Glycyrrhiza glabra L. (licorice) and have been used in treating hepatic disease. It has been shown that there are specific GA and glycyrrhizin binding sites on the cellular membrane of rat hepatocytes in vitro and that the number of binding sites for GA is much higher than that for glycyrrhizin; ${ }^{17,18}$ furthermore, the amount of GA receptors in tumor tissue has been found to be 1.5 - to 5 -fold that in normal tissue. ${ }^{19}$ Recently, some GA-modified vectors have been developed, including GA-PEG/chitosan nanoparticles, ${ }^{20}$ GA-modified poly(ethylene glycol)-b-poly(c-benzyl l-glutamate) micelles, ${ }^{21}$ GA-modified liposomes, ${ }^{22}$ and GA-PEGylated cationic liposomes. ${ }^{23}$ All of these results imply that GA may be used as a novel ligand for hepatocyte-targeting.

In this study, OX liposomes surface-modified with GA were developed by the film-dispersion method. Their morphology, physical and chemical properties, and in vitro release performance were examined; unmodified liposomes were also investigated, as a contrast. Moreover, pharmacokinetics and biodistribution studies of OX-GAliposomes were done to provide a reference for clinical application.

\section{Materials and methods}

\section{Materials}

OX (Figure 1A) (purity 99.3\%) was supplied by Zhongcheng Pharma Co, Ltd (Hubei, People's Republic of China). Egg phosphatidylcholine and high-purity cholesterol were donated by Phospholipid Tech Ltd, Shanghai, People's Republic of China. Carboplatin (Figure 1B) (internal standard) was obtained from the Shanghai Institute of Materia Medica, Chinese Academy of Sciences, Shanghai, People's Republic of China. All other chemicals and reagents were of at least analytical grade. Purified water prepared from a Milli-Q ${ }^{\circledR}$ deionization unit (Millipore, Bedford, MA, USA) was used throughout.

The experiments were performed on rats weighing $210 \pm 20 \mathrm{~g}$ and mice weighing $22 \pm 2 \mathrm{~g}$. The animals were kept in cages at a temperature of $25^{\circ} \mathrm{C} \pm 2^{\circ} \mathrm{C}$, and with a $12: 12$ light-dark cycle. Food and water were freely available. All experiments were performed in strict accordance with the Guide for the Care and Use of Laboratory Animals as adopted by the China National Institutes of Health.

\section{Preparation of GA-OX-liposomes}

Liposomes were prepared by a modified film-dispersion method. ${ }^{24}$ 3-Succinyl-30-stearyl glycyrrhetinic acid (18-GA-Suc), synthesized previously, ${ }^{25}$ was used to modify the OX-liposomes. Briefly, a mixture of egg phosphatidylcholine, cholesterol, 18-GA-Suc, and OX (weight: 100, 25,7 , and $10 \mathrm{mg}$, respectively) was dissolved in $10 \mathrm{~mL}$ dichloromethane in a round-bottomed flask. The organic solvent was removed at $25^{\circ} \mathrm{C}-30^{\circ} \mathrm{C}$ by rotary evaporation. The vacuum was maintained overnight to remove any traces of solvent. Then, the resulting lipid film was hydrated with a $4 \mathrm{~mL}$ phosphate-buffered saline (PBS) buffer ( $\mathrm{pH} 7.4)$ at $37^{\circ} \mathrm{C}$ for 2 hours, followed by sonication for ten cycles at 1,000 bar with an ultrasound probe (EmulsiFlex ${ }^{\mathrm{TM}}-\mathrm{B} 15$;
A

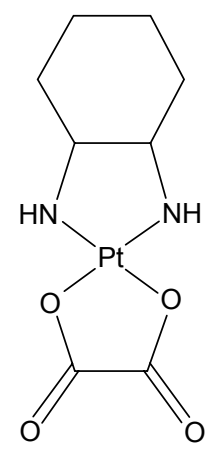

B

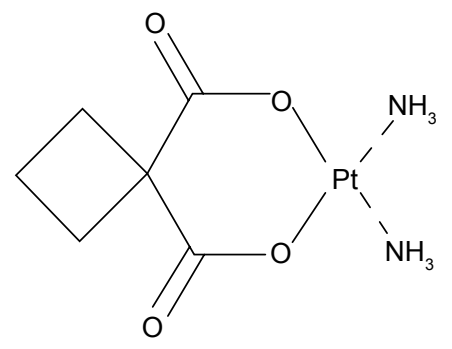

Figure I The structure of oxaliplatin (A) and carboplatin (B). 
Avestin Inc., Ottawa, ON, Canada) to form the GA-OXliposomes. Production of the OX liposomes was similar to that for GA-OX-liposomes, but the weight ratio of egg phosphatidylcholine, cholesterol, and OX was, respectively, 100,25 , and $10 \mathrm{mg}$.

\section{Characterization}

The morphology of the GA-OX-liposomes was observed using a transmission electron microscopy (TEM) apparatus (JEM-1230; JEOL, Tokyo, Japan). A drop of sample placed on a carbon-coated copper grid was negatively stained with $2 \%$ phosphotungstic acid and then viewed and photographed.

Particle size and zeta potential of the liposomes were measured using a Zetasizer Nano ZS analyzer (Malvern Instruments, Malvern, UK). Briefly, $15 \mu \mathrm{L}$ of prepared liposomes were diluted 100-fold with ultrapure water and shaken, prior to its measurement at $25^{\circ} \mathrm{C}$. The dynamic light scattering data was collected using a helium laser as the light source, and mean results were provided by photon correlation spectroscopy.

\section{Entrapment efficiency (EE\%) and drug loading (DL\%)}

The DL\% and EE\% were calculated as described earlier. ${ }^{26}$ Firstly, OX was extracted from the liposomes with $0.25 \mathrm{~mol} / \mathrm{L}$ of sodium chloride solution and methanol (3:7 $\mathrm{v} / \mathrm{v})$, and then the extracted solution was properly diluted prior to high-performance liquid chromatography (HPLC) analysis. The content of $\mathrm{OX}$ in the liposomes was determined by the HPLC method described below. Then, DL\% and EE\% were calculated according to Equations 1 and 2:

$$
\begin{gathered}
\mathrm{DL} \%=\mathrm{WM} /(\mathrm{WP}+\mathrm{WM}) \times 100 \\
\mathrm{EE} \%=\mathrm{WM} / \mathrm{WF} \times 100,
\end{gathered}
$$

where WP is the weight of initial feeding polymer, WM is the weight of drug incorporated in the liposomes, and WF is the weight of the initial feeding drug.

\section{In vitro release}

In vitro drug release was investigated via the dialysis bag method. First, 2 mL of GA-OX-liposomes, OX-liposomes, and free $\mathrm{OX}$ were each placed in cellulose ester dialysis bags (molecular weight $=10,000$ ). These bags were then put into $30 \mathrm{~mL}$ of PBS buffer $(\mathrm{pH}=7.4)$ and heated at $37^{\circ} \mathrm{C} \pm 0.5^{\circ} \mathrm{C}$. The OX contents $(1 \mathrm{~mL})$ in the dialysate, at $0.5,1,1.5,2$,
3, 4, 6, 8, 12, 16, and 24 hours, were determined by HPLC. The supernatant $(10 \mu \mathrm{L})$ was then directly injected into the HPLC system and analyzed for the released OX. The release profiles were plotted and fit using different in vitro release models.

\section{Stability}

Stability studies of the liposomes were carried out at temperature of $25^{\circ} \mathrm{C} \pm 2{ }^{\circ} \mathrm{C}$ and relative humidity of $60 \% \pm 5 \%$ for a period of 2 weeks and at $4^{\circ} \mathrm{C} \pm 1^{\circ} \mathrm{C}$ for 6 months, according to the guideline of International Conference on Harmonisation. ${ }^{27}$ The accelerated storage temperature and long-term storage temperature were $25^{\circ} \mathrm{C} \pm 2^{\circ} \mathrm{C}$ and $4^{\circ} \mathrm{C} \pm 1^{\circ} \mathrm{C}$, respectively. The stored samples were tested for their $\mathrm{EE} \%$, particle size distribution, and physical changes.

\section{Pharmacokinetics evaluation}

Eighteen rats were used to investigate the effect of liposome formulation on the pharmacokinetics of $\mathrm{OX}$ after intravenous (IV) administration. Rats were divided into three groups at random and given a single dose of $20 \mathrm{mg} / \mathrm{kg}$ of GA-OX-liposomes, OX-liposomes, and free OX, respectively, by venous injection. Blood samples $(0.5 \mathrm{~mL})$ were collected into heparinized tubes from the caudal vein at 2, 5, 15, and 45 minutes and at 1, 2, 4, 8, 12, and 24 hours after IV administration. Blood was immediately processed for plasma by centrifugation at $3,000 \times \mathrm{g}$ for 10 minutes. Plasma samples were frozen and maintained at $-70^{\circ} \mathrm{C}$ until analysis.

\section{Histology studies}

After pharmacokinetics evaluation, all 18 rats were used to investigate the histopathological change of liposomes after a single IV administration of the formulation $(20 \mathrm{mg} / \mathrm{kg})$. Animals (including the free OX control group) were anesthetized, and their hearts, livers, spleens, lungs, and kidneys were dissected and washed with cold saline. The organs were pressed between filter pads, weighed, and then fixed in 10\% neutral formalin, using standard techniques, and stained with hematoxylin and eosin for histopathological examination. All tissue samples were examined and graded under a light microscope, with $500 \times$ magnification.

\section{Biodistribution studies}

Ninety Kunming strain mice were used in the experiment to assess the effect of liposomes formulation on the biodistribution of OX after IV administration. The mice were divided into three groups at random and given a single dose 
of $20 \mathrm{mg} / \mathrm{kg}$ of GA-OX-liposomes, OX-liposomes, and free OX, respectively, by caudal vein injection. At 1, 4, 8, 12, and 24 hours after drug injection, each animal $(n=5$ for each time point) was euthanized, and the heart, liver, spleen, lung, and kidney were collected. Tissue samples were washed in ice-cold saline, blotted with paper towel to remove excess fluid, weighed, and stored at $-70^{\circ} \mathrm{C}$ until assessed for drug concentration by HPLC.

\section{HPLC analysis}

HPLC was carried out by a Waters chromatograph (Waters Corp, Milford, MA USA) using the Diamonsil ${ }^{\circledR} \mathrm{C} 18$ reversephase column $(250 \mathrm{~mm} \times 4.6 \mathrm{~mm}, 5 \mathrm{~mm})$ at room temperature. The mobile phase consisted of $0.25 \mathrm{~mol} / \mathrm{L}$ of sodium chloride solution and methanol $(30: 70 \mathrm{v} / \mathrm{v})$. The injection volume was $10 \mu \mathrm{L}$. The flow rate was $1 \mathrm{~mL} / \mathrm{min}$. The effluent was monitored at $254 \mathrm{~nm}$.

Diethyldithiocarbamate solution $(0.5 \mathrm{~mL}), \mathrm{NH}_{3}-\mathrm{NH}_{4} \mathrm{Cl}$ buffer ( $\mathrm{pH} 9.0,0.5 \mathrm{~mL})$, and carboplatin solution $(10 \mu \mathrm{L}$, $1 \mathrm{mg} / \mathrm{mL})$ were added into the plasma $(100 \mu \mathrm{L})$ or tissues $(100 \mathrm{mg})$. After incubation in the water bath $\left(37^{\circ} \mathrm{C}\right)$ for 30 minutes, the ether $(5 \mathrm{~mL})$ was added to the mixture. After centrifugation for 20 minutes $(3,000 \mathrm{rpm})$, the supernatant

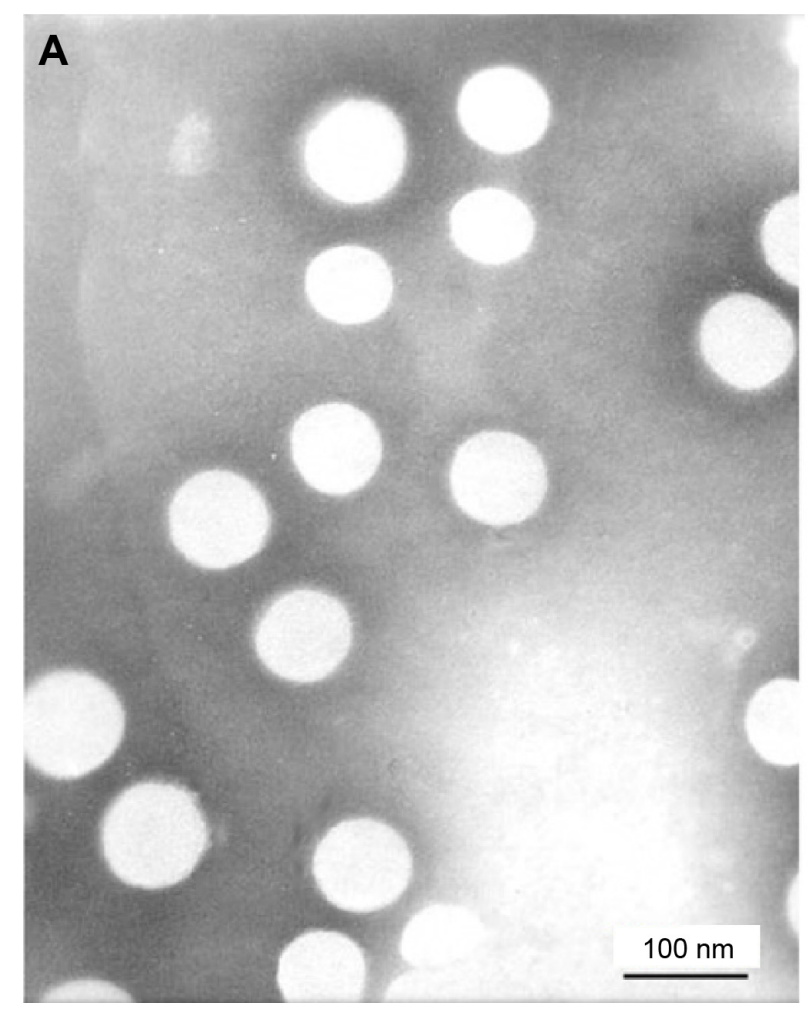

was kept in water bath $\left(50^{\circ} \mathrm{C}\right)$ to evaporate the ether. Finally, chloroform was added into the residue, and the solution was centrifuged for 10 minutes (12,000 rpm). Finally, $20 \mu \mathrm{L}$ of supernatant was injected into the HPLC system for analysis.

\section{Statistical analysis}

Results were presented as the mean \pm standard deviation (SD). Analysis of variance (ANOVA) was used to identify the statistical significance of the differences among groups. Statistical significance was evaluated using Student's $t$-test for the single or multiple comparisons of the experimental groups.

\section{Results and discussion \\ Characterization}

In this study, OX-liposomes surface-modified with GA were developed using a film-dispersion method. The morphology of the liposomes was observed by TEM, and the results were displayed in Figure 2. The TEM image shows that most liposomes were spherical particles with similar size and uniform dispersion. The average sizes of the OXliposomes and GA-OX-liposomes, both $90 \mathrm{~nm}$, are displayed in Table 1. The two liposomes were negatively charged, with

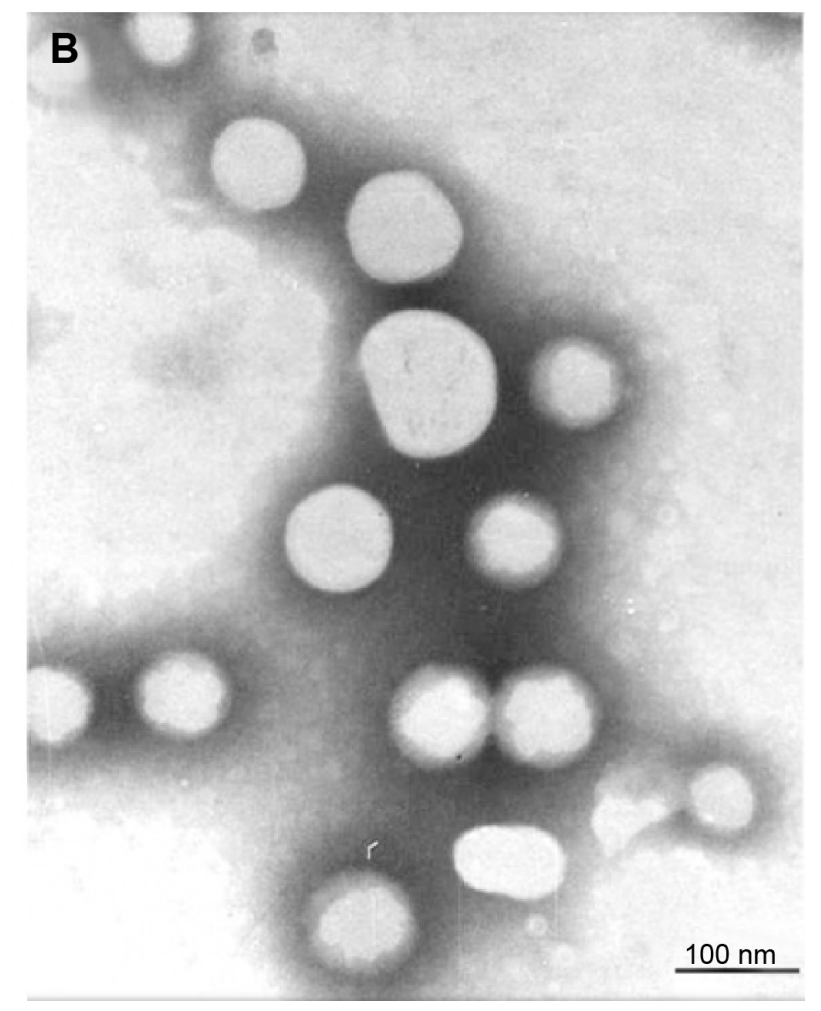

Figure 2 Transmission electron microscope photographs of liposomes. (A) GA-OX-liposomes. (B) OX-liposomes.

Notes: Magnification: $\times 6,000$. Scale bar $=100 \mathrm{~nm}$.

Abbreviations: GA, glycyrrhetinic acid; OX, oxaliplatin. 
Table I The characterization of the liposomes $(n=3)$

\begin{tabular}{lllll}
\hline Sample & Particle size $(\mathrm{nm})$ & Zeta potential $(\mathbf{m V})$ & Entrapment efficiency $(\%)$ & Drug loading $(\%)$ \\
\hline OX-liposomes & $85.3 \pm 2.6$ & $-20.6 \pm 2.2$ & $91.6 \pm 4.6$ & $10.2 \pm 1.3$ \\
GA-OX-liposomes & $93.2 \pm 3.1$ & $-21.3 \pm 2.9$ & $89.8 \pm 5.1$ & $9.7 \pm 1.1$ \\
\hline
\end{tabular}

Abbreviations: GA, glycyrrhetinic acid; OX, oxaliplatin.

zeta potentials of -20.6 and $-21.3 \mathrm{mV}$, respectively, and the $\mathrm{EE} \%$ values of both were higher than $94 \%$. No significant changes were observed following the addition of 18-GA-Suc to the liposomes.

It is crucial to select proper quality attributes as the target profile at the beginning, for optimization of GA-OXliposomes. Since the EE\% affects the quality and clinical effects of the liposomes to a great extent, ${ }^{28}$ the evaluation of $\mathrm{EE} \%$ is a regulatory requirement. Additionally, the particle size should be controlled, considering the principle of injection administration. A previous report pointed out that when the particle size is less than $100 \mathrm{~nm}$, aggregation in the liver is obvious, because it is trapped by the sinusoidal tubules in the liver and spleen. ${ }^{29}$ In a liposome system, the hydrophilic compound is usually encapsulated into the inner water phase, while the lipophilic compound is generally entrapped between lipid bilayers.

\section{In vitro release}

The in vitro drug release behavior of GA-OX-liposomes was studied using a dialysis method. The release profiles of free OX, OX-liposomes, and GA-OX-liposomes are shown in Figure 3. It was noticed that the release rate of OX-liposomes was significantly lower than that of free drug. Over $95 \%$ of the hydrophilic free OX was released in the initial 4 hours. In comparison, the OX-liposomes released $39 \%$ of drug in the initial 4 hours, then $30 \%$ of the entrapped OX was further released during the subsequent 20-hour incubation. The OX release profile was prominently prolonged by the liposomal encapsulation. However, no significant changes were observed in terms of release characteristics following the addition of 18-GA-Suc to the liposomes. The in vitro release was kinetically analyzed according to the zero-order, first-order, Higuchi, and Weibull models. The relatively high correlation coefficient values obtained from analyzing the amount of drug released versus the square root of time depicted that release followed the Weibull model, as was shown in Table 2. In vitro data showed that the application of liposomes could prolong the OX release. The sustained release of OX revealed its applicability as a drug delivery system that could minimize the exposure of healthy tissues, while increasing the accumulation of therapeutic drug in tumor sites.

\section{Stability}

The particle size and EE\% in the long-term storage conditions did not vary to a large extent in the GA-OX-liposomes, and a maximum size increase of $4.4 \mathrm{~nm}$ was seen in the 6 months after the date of manufacture. The formulations were stable for 0.5 month under accelerated storage conditions at $25^{\circ} \mathrm{C} \pm 2{ }^{\circ} \mathrm{C}$ and $60 \% \pm 5 \%$ relative humidity. A maximum particle size increase of $2.4 \mathrm{~nm}$ was observed. The average particle size did not vary appreciably, and the physical-chemical characteristics changes were found to be

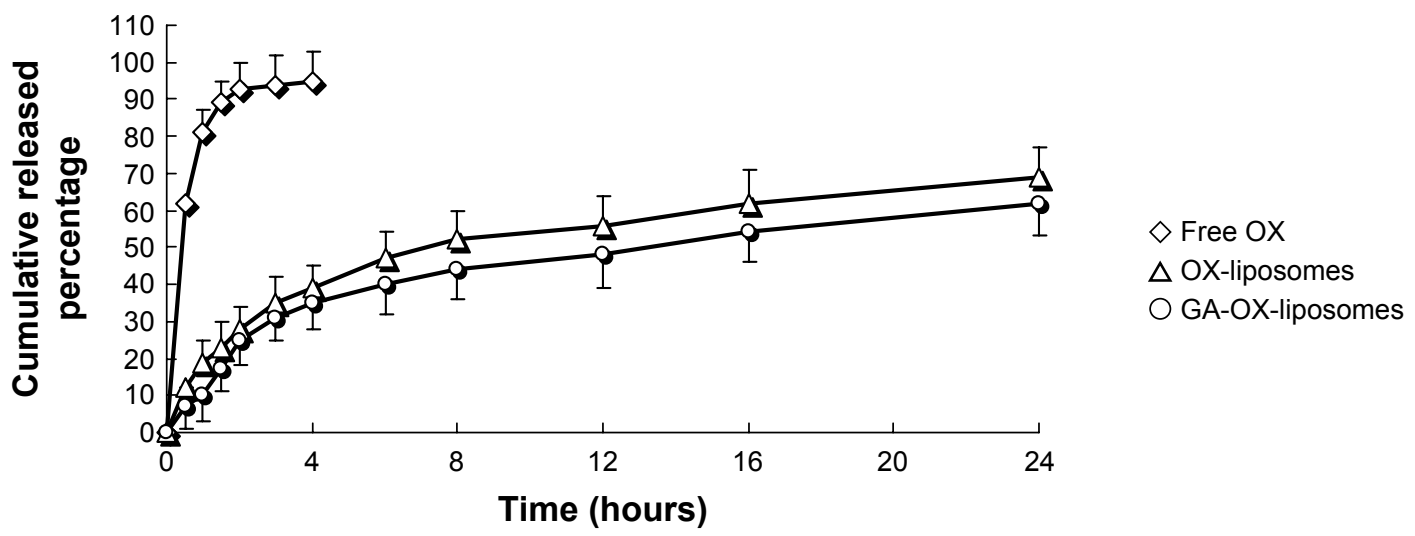

Figure 3 In vitro release profiles of different OX formulations.

Notes: Release experiments were carried out in PBS ( $\mathrm{pH} 7.4$ ), at $37^{\circ} \mathrm{C} \pm 0.5^{\circ} \mathrm{C}$. Each point represents the mean value of three different experiments \pm SD. Abbreviations: GA, glycyrrhetinic acid; OX, oxaliplatin; PBS, phosphate-buffered saline; SD, standard deviation. 
Table 2 Correlation coefficients for kinetic analysis of release data for OX formulations

\begin{tabular}{lllll}
\hline Formulation & \multicolumn{4}{l}{ Correlation coefficient $(\boldsymbol{r})$} \\
\cline { 2 - 5 } & Zero order & First order & Higuchi & Weibull \\
\hline OX-liposomes & 0.9342 & 0.9642 & 0.9718 & 0.9963 \\
GA-OX-liposomes & 0.9433 & 0.9654 & 0.9747 & 0.9979 \\
\hline
\end{tabular}

Abbreviations: GA, glycyrrhetinic acid; OX, oxaliplatin.

negligible and had no impact on the quality of the formulations (Table 3).

\section{Pharmacokinetic studies}

The plasma concentration-time profiles of free OX, OX-liposomes, and GA-OX-liposomes after IV administration are shown in Figure 4, and the pharmacokinetic parameters are summarized in Table 4. The results showed that the plasma concentration-time curves of free OX, OX-liposomes, and GA-OX-liposomes all fit with the open two-compartment model. As shown in Table 4, the distribution half-life of OXliposomes ( 0.63 hour) and GA-OX-liposomes ( 0.58 hour) was shorter than that of free OX injection ( 0.76 hour), suggesting that OX-liposomes were taken up by other tissues more rapidly than was free OX. The area under the curve of $\mathrm{OX}$ in the GA-liposomes and liposomes was, respectively, 4.4- and 3.2-fold that of OX injection $(P<0.05)$. The clearance of OX-liposomes and GA-OX-liposomes was 17.6 and $15.9 \mathrm{~L} / \mathrm{h}$, respectively, smaller than that $(28.3 \mathrm{~L} / \mathrm{h})$ of the free OX. Conversely, free OX had a larger clearance as compared with the free OX, possibly due to the fact that the injection had a larger volume of distribution than did the liposome. The relatively short time to reach maximum plasma concentration of OX-liposomes suggests a sustained-release profile of liposomes in vivo, which is consistent with the results of the in vitro release study. The increased area under the curve and maximum plasma concentration of the OX-liposomes and GA-OX-liposomes demonstrates an increased absorption.

\section{Histology studies}

Histopathological examination of heart, liver, spleen, lung, and kidney was carried out for detection of any damage to the tissue. Microphotographs were taken of heart, liver, spleen, lung, and kidney, 24 or more hours after a single IV administration (20 mg/kg) (Figure 5). Free OX was used as the control. No severe signs, such as appearance of epithelial necrosis or sloughing of epithelial cells, were detected.

\section{Biodistribution studies}

The free OX, OX-liposomes, and GA-OX-liposomes were all taken up by the heart, liver, spleen, lungs, and kidneys of mice. Figures $6-8$ reflect the tissue distribution results in samples taken $1,4,8,12$, and 24 hours after injection of the OX preparations into the caudal vein of mice. The total amount of drug accumulated in each organ within 24 hours $\left(\mathrm{AUC}_{0-\mathrm{t}}\right)$ was calculated, and the results are shown in Table 5. OX-liposomes were passively targeted to the tissues of heart, liver, lung, and kidneys, where the AUC value was 1.24- to 1.77-fold higher than for the free OX injection group, but was 0.94 -fold lower in spleen. In contrast, GA-OX-liposomes rapidly accumulated in liver, reaching particularly high levels in the liver just 1 hour after injection. The drug concentration in tissues indicated that the GA-modified liposomes delivered OX mainly to the liver after IV administration. In the liver,

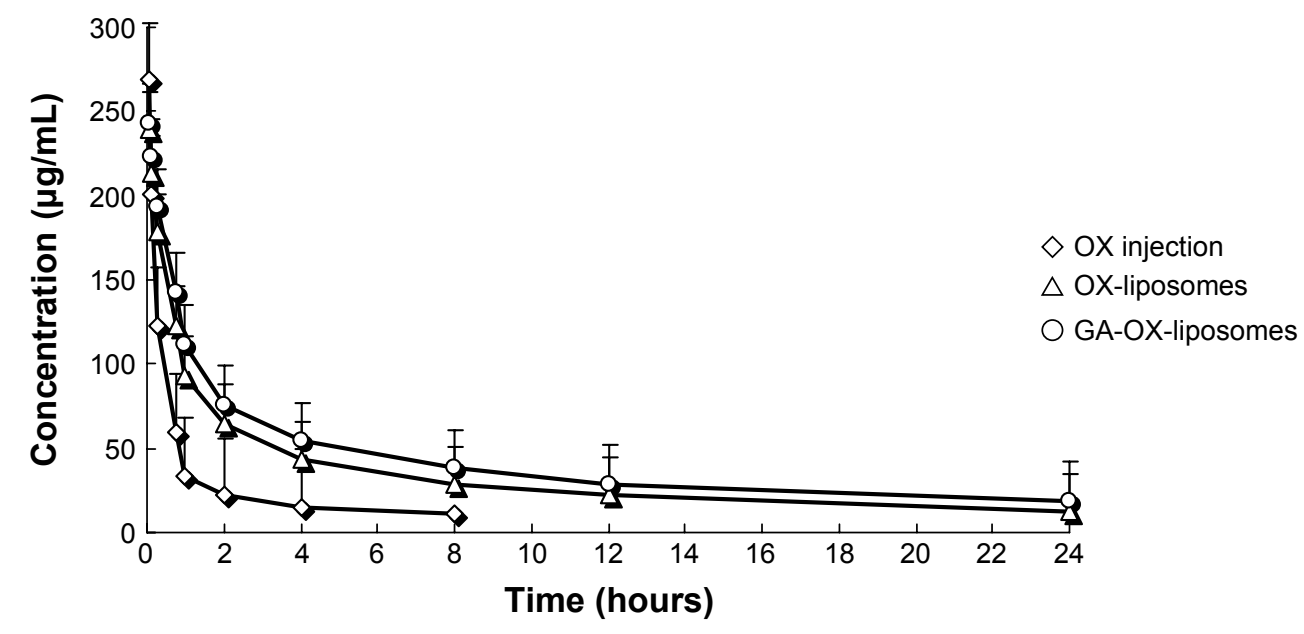

Figure 4 Mean plasma concentration-time profiles of OX after IV administration of a single $20 \mathrm{mg} / \mathrm{kg}$ dose of free OX and liposomes to rats. Note: Each point represents the mean \pm SD of six rats.

Abbreviations: GA, glycyrrhetinic acid; IV, intravenous; OX, oxaliplatin; SD, standard deviation. 
Table 3 Stability data of GA-OX-liposomes

\begin{tabular}{|c|c|c|c|c|c|c|}
\hline \multirow[t]{2}{*}{ Time (month) } & \multicolumn{3}{|l|}{$4^{\circ} \mathrm{C}$} & \multicolumn{3}{|l|}{$25^{\circ} \mathrm{C}$} \\
\hline & Morphology & $\begin{array}{l}\text { Particle } \\
\text { size }(\mathrm{nm})\end{array}$ & $\begin{array}{l}\text { Entrapment } \\
\text { efficiency (\%) }\end{array}$ & Morphology & $\begin{array}{l}\text { Particle } \\
\text { size }(\mathrm{nm})\end{array}$ & $\begin{array}{l}\text { Entrapment } \\
\text { efficiency (\%) }\end{array}$ \\
\hline 0.25 & - & - & - & No changes & $93.4 \pm 3.2$ & $89.4 \pm 3.7$ \\
\hline 0.5 & - & - & - & No changes & $95.6 \pm 5.1$ & $88.3 \pm 4.6$ \\
\hline I & No changes & $93.7 \pm 3.5$ & $89.7 \pm 4.5$ & - & - & - \\
\hline 3 & No changes & $95.8 \pm 5.3$ & $87.5 \pm 3.9$ & - & - & - \\
\hline 6 & No changes & $97.6 \pm 5.9$ & $86.4 \pm 4.3$ & - & - & - \\
\hline
\end{tabular}

Note: Absence of a value signifies "not detected".

Abbreviations: GA, glycyrrhetinic acid; OX, oxaliplatin.

Table 4 Pharmacokinetic parameters of the three formulations

\begin{tabular}{llll}
\hline Parameter & Formulations & \\
\cline { 2 - 4 } & Injection & OX-liposomes & GA-OX-liposomes \\
\hline $\mathrm{t}_{1 / 2 \alpha}(\mathrm{h})$ & $0.76 \pm 0.3$ & $0.63 \pm 0.4$ & $0.58 \pm 0.7$ \\
$\mathrm{t}_{1 / 2 \beta}(\mathrm{h})$ & $16.2 \pm 3.1$ & $21.4 \pm 4.7^{*}$ & $27.3 \pm 3.9^{*}$ \\
$\mathrm{C}_{\max }(\mu \mathrm{g} / \mathrm{mL})$ & $269.6 \pm 58.3$ & $239.5 \pm 36.7$ & $243.1 \pm 24.6$ \\
$\mathrm{AUC}_{0-\mathrm{t}}(\mu \mathrm{g} \cdot \mathrm{h} / \mathrm{mL})$ & $239.7 \pm 28.1$ & $783.1 \pm 37.6^{*}$ & $996.3 \pm 56.8^{*}$ \\
$\mathrm{AUC}_{0-\infty}(\mu \mathrm{g} \cdot \mathrm{h} / \mathrm{mL})$ & $275.4 \pm 36.8$ & $882.4 \pm 78.4^{*}$ & $1205.6 \pm 83.4^{*}$ \\
$\mathrm{MRT}(\mathrm{h})$ & $13.5 \pm 3.3$ & $22.9 \pm 4.8^{*}$ & $25.7 \pm 5.2^{*}$ \\
$\mathrm{CL}(\mathrm{L} / \mathrm{h})$ & $28.3 \pm 5.9$ & $17.6 \pm 3.6^{*}$ & $15.9 \pm 4.7^{*}$ \\
\hline
\end{tabular}

Note: $* P<0.05$ (vs free $O X$ ).

Abbreviations: $A \cup C_{0-t}$, area under the drug concentration-time curve values (from 0 to $t$ time); $A \cup C_{0-\infty}$, area under the drug concentration-time curve values (from 0 to $\infty$ time); $C L$, clearance; $C_{\text {max }}$, peak concentration; GA, glycyrrhetinic acid; MRT, mean residence time; $O X$, oxaliplatin; $t_{1 / 2 \alpha}$, biological half-life $A$ lpha; $t_{1 / 2 \beta}$, biological half-life Beta.

A
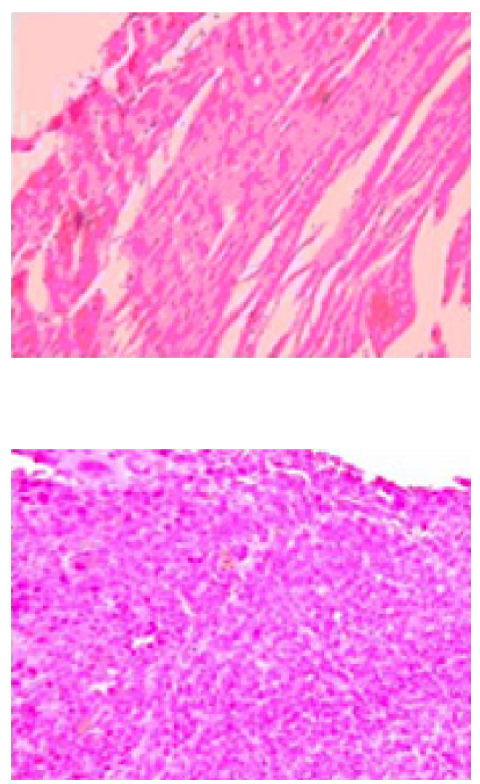

B

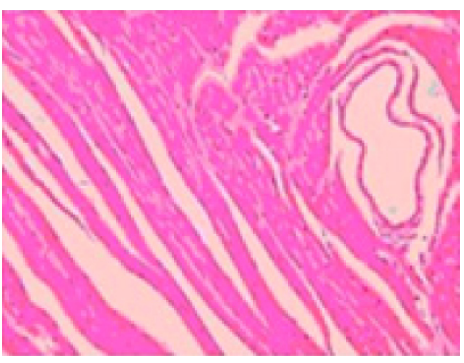

Heart

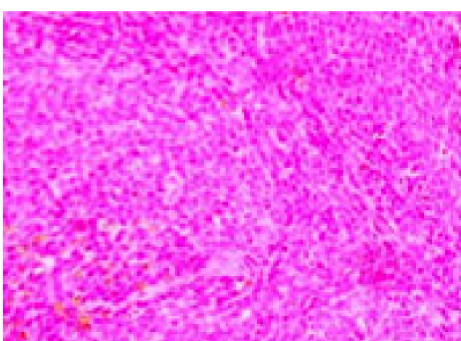

Liver
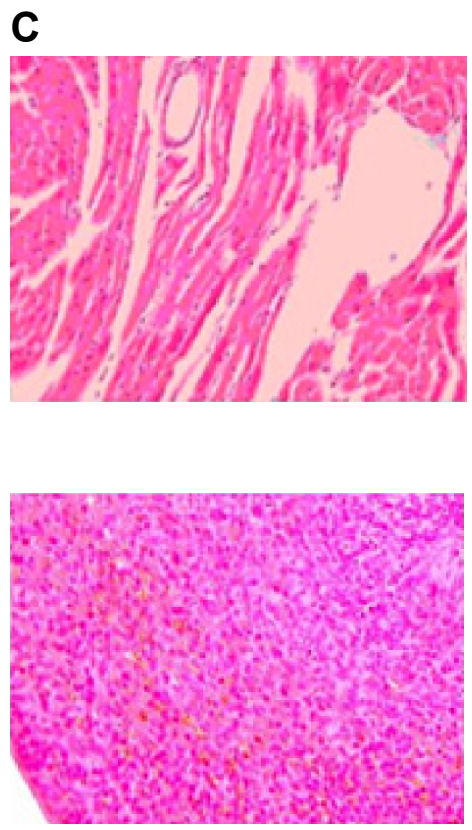

Figure 5 (Continued) 

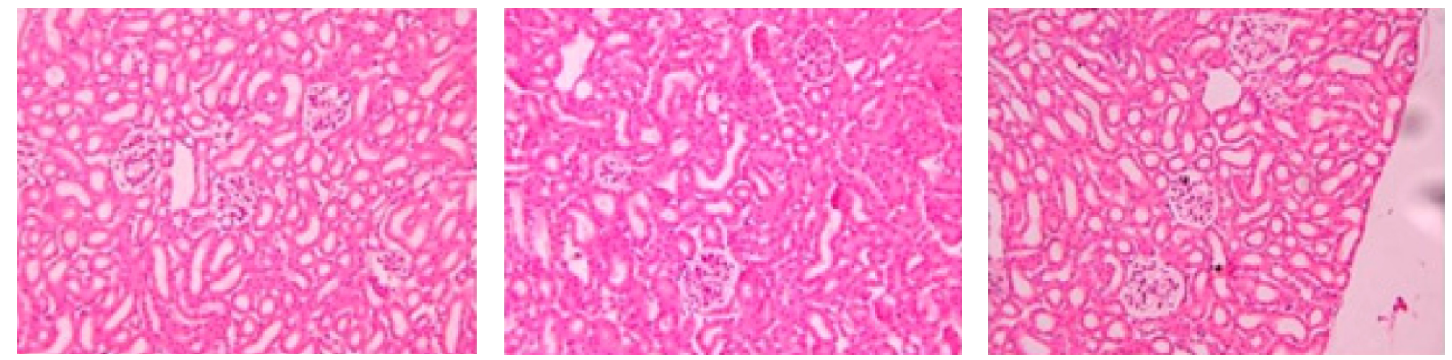

Spleen
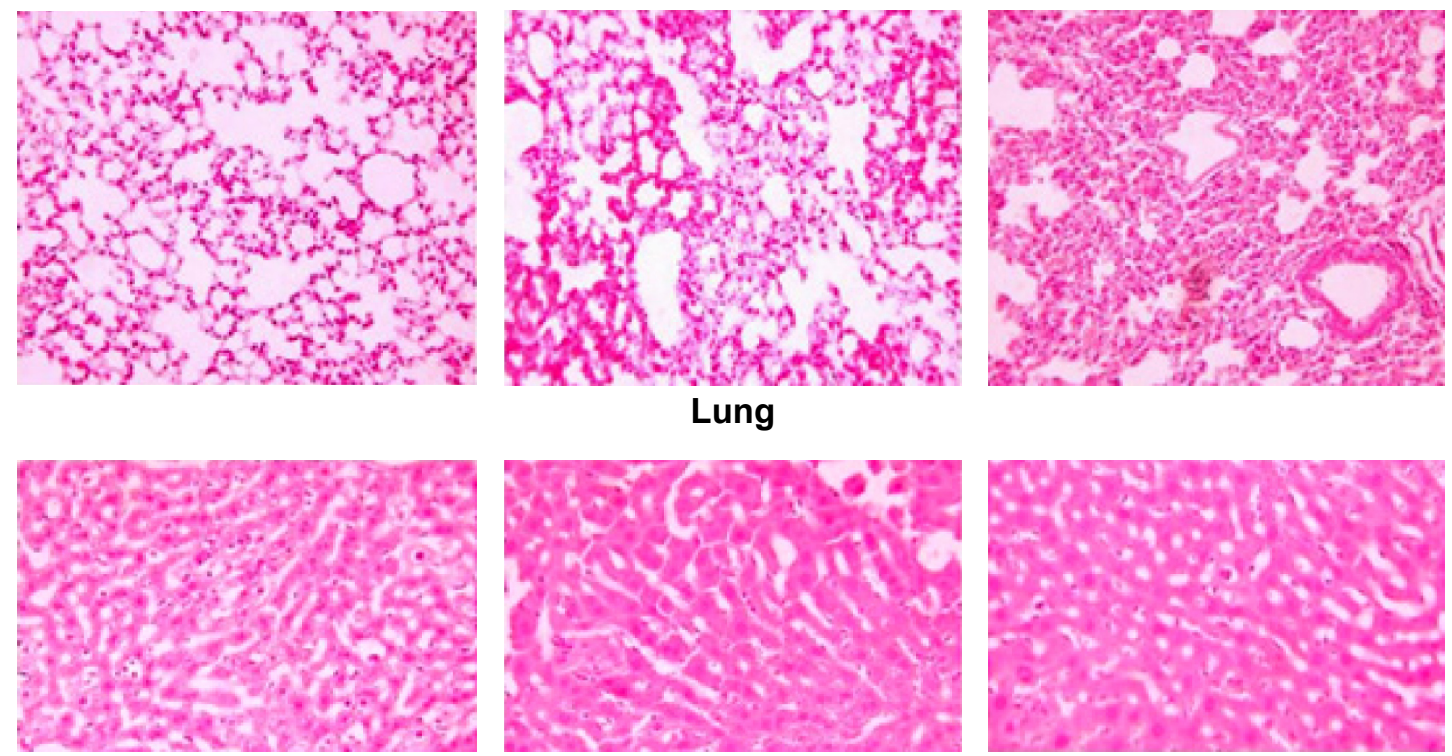

\section{Kidney}

Figure 5 Histological examination of each tissue.

Notes: The microphotographs were taken of heart, liver, spleen, lung, and kidney, 24 or more hours after a single IV administration (20 mg/kg). Sections were stained with H\&E for the analysis of tissue morphology and the level of inflammation. (A) free OX. (B) OX-liposomes. (C) GA-OX-liposomes.

Abbreviations: GA, glycyrrhetinic acid; H\&E, hematoxylin and eosin, IV, intravenous; OX, oxaliplatin.

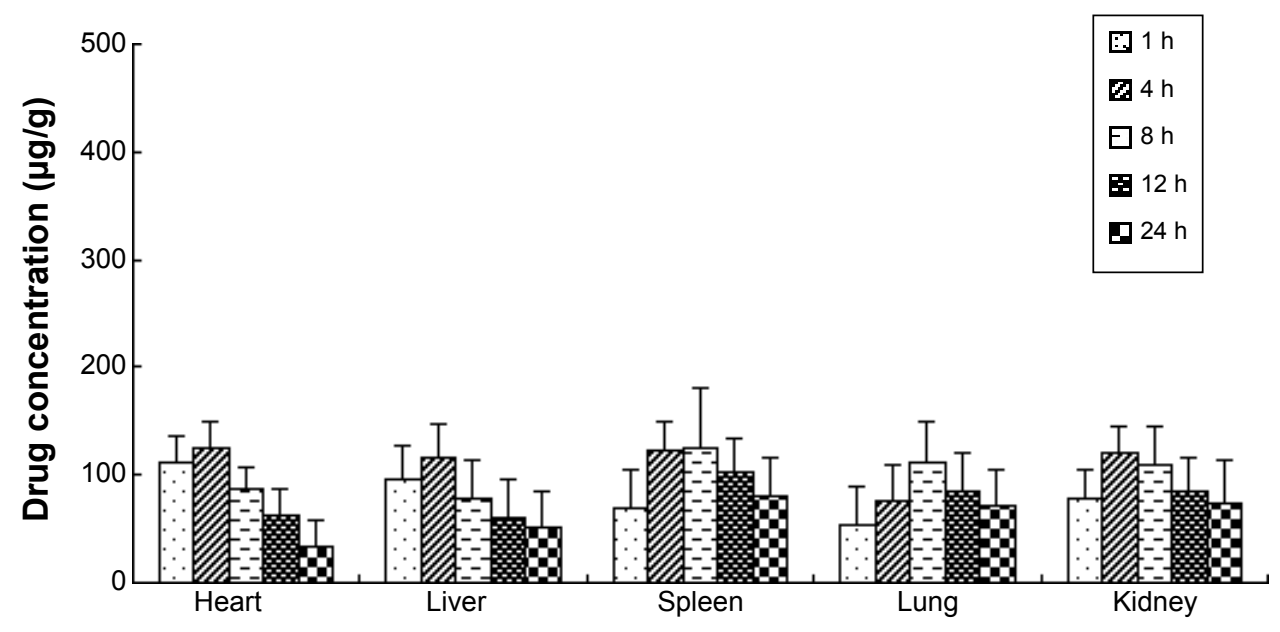

Figure 6 Distribution in tissue in mice, following IV administration of a single $20 \mathrm{mg} / \mathrm{kg}$ dose of free OX.

Note: Each point represents the mean \pm SD of six mice.

Abbreviations: IV, intravenous; OX, oxaliplatin; SD, standard deviation; h, hour. 


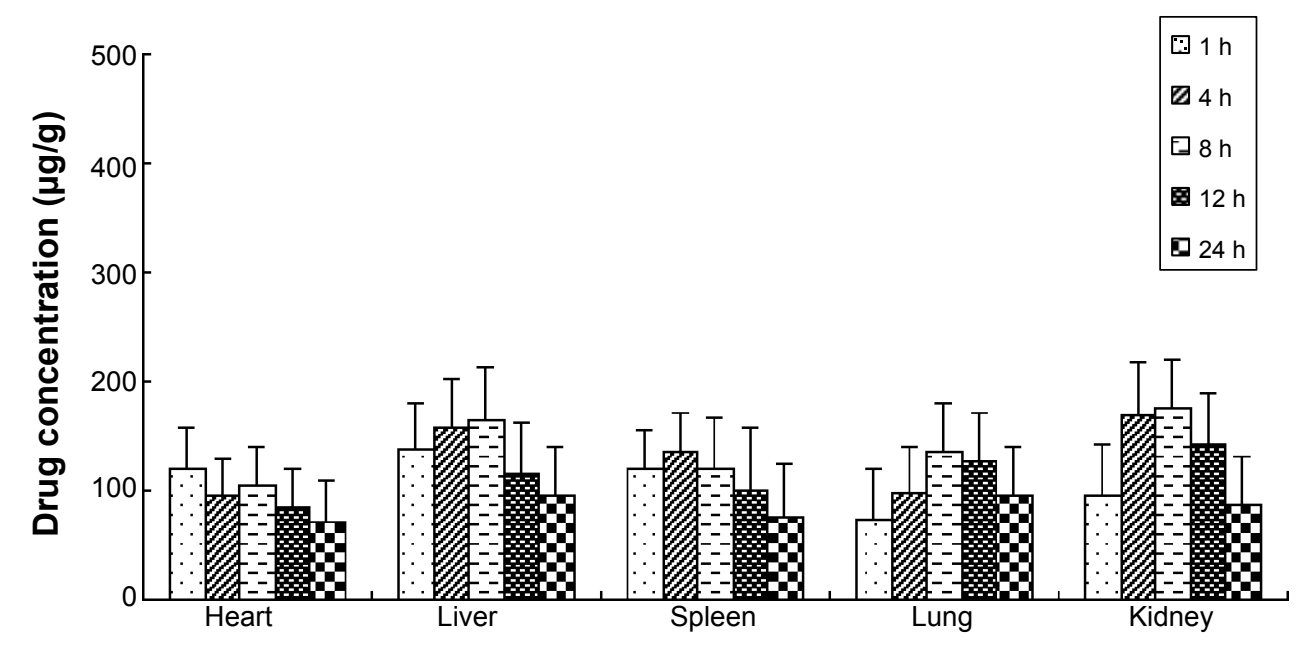

Figure 7 Distribution in tissue in mice, after IV administration of a single $20 \mathrm{mg} / \mathrm{kg}$ dose of OX-liposomes.

Note: Each point represents the mean \pm SD of six mice.

Abbreviations: IV, intravenous; OX, oxaliplatin; SD, standard deviation; h, hour.

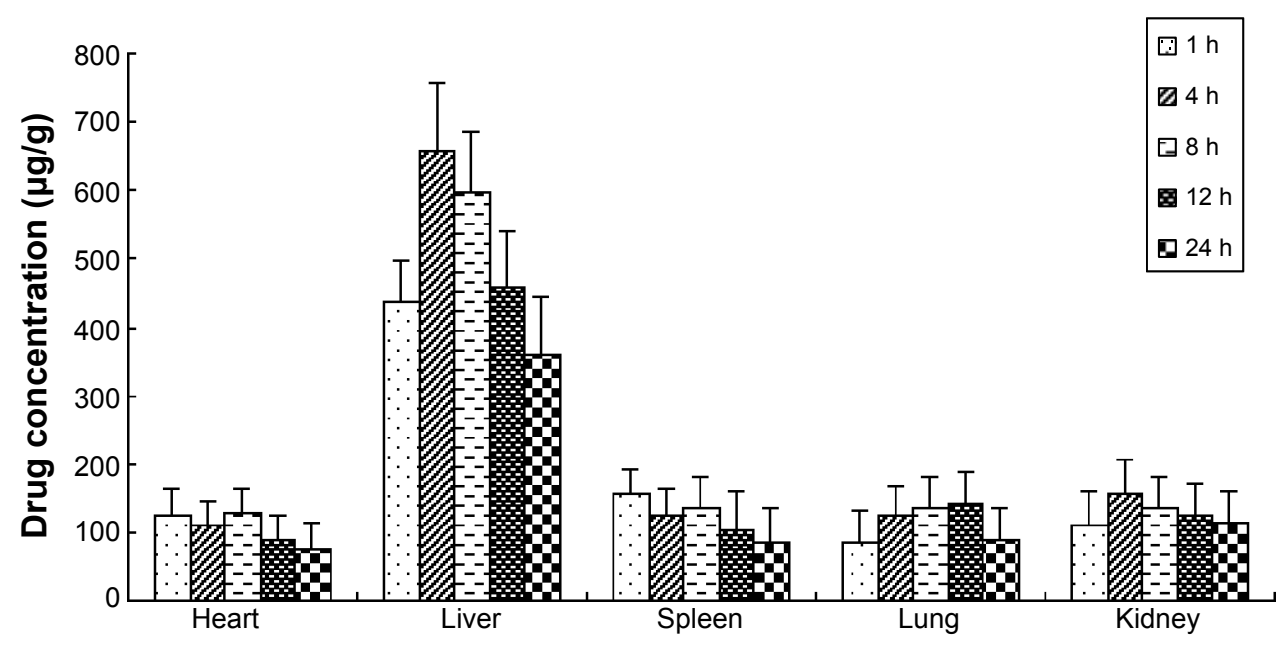

Figure 8 Distribution in tissue in mice, after following IV administration of a single $20 \mathrm{mg} / \mathrm{kg}$ dose of GA-OX-liposomes.

Note: Each point represents the mean \pm SD of six mice.

Abbreviations: GA, glycyrrhetinic acid; IV, intravenous; OX, oxaliplatin; SD, standard deviation; h, hour.

Table 5 The $\mathrm{AUC}_{0-24 \mathrm{~h}}$ of $\mathrm{OX}$ in tissues after IV administration of free $\mathrm{OX}$ and liposomes to mice $(\mathrm{n}=6)$

\begin{tabular}{llllll}
\hline Formulation & Heart & Liver & Spleen & Lung & Kidney \\
\hline free OX & 1,646 & 1,648 & 2,333 & 1,901 & 2,104 \\
OX-liposomes & 2,039 & 2,910 & 2,198 & 2,572 & 3,082 \\
GA-OX-liposomes & 2,257 & $1 \mathrm{I}, 162$ & 2,547 & $2,78 \mathrm{I}$ & 2,952 \\
Ratio $^{\mathrm{a}}$ & 1.37 & $6.77^{*}$ & 1.09 & 1.46 & 1.40 \\
Ratio $^{\mathrm{b}}$ & $1.1 \mathrm{I}$ & $3.84^{*}$ & 1.16 & 1.08 & 0.96 \\
Ratio $^{c}$ & 1.24 & 1.77 & 0.94 & 1.35 & 1.46 \\
\hline
\end{tabular}

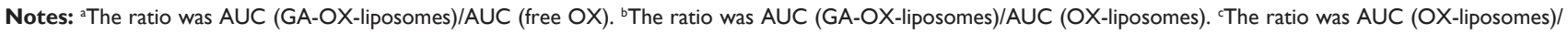
AUC (free OX). *P<0.05.

Abbreviations: AUC, area under the drug concentration-time curve values; GA, glycyrrhetinic acid; IV, intravenous; OX, oxaliplatin. 
there were significant differences between the GAOX-liposomes; OX-liposomes, and free OX injection $(P<0.05)$, but not in other tissues. A prior in vitro study found that specific GA binding sites exist on the cellular membranes of rat hepatocytes. ${ }^{30}$ Another study indicated that GA-modified nanocarriers had increased affinity for human hepatic or HCC. ${ }^{31}$ However, no studies specifically looked at the application of GA and OX. The present study shows that the concentration of OX was higher with GA liposomes, indicating that GA modification is a good candidate strategy for the targeting of hepatic cells and that this mechanism deserves further study.

\section{Conclusion}

In this study, OX liposomes surface-modified with GA were developed by the film-dispersion method. In vitro data showed that the application of liposomes could prolong the OX release. The TEM image showed that most liposomes were spherical particles with similar size and uniform dispersion. In vivo, the increased area under the curve and maximum plasma concentration of the OX-liposomes and GA-OX-liposomes demonstrated an increased absorption. The drug concentration in tissues indicated that the GAmodified liposomes delivered OX mainly to the liver, after IV administration. In addition, no severe signs, such as appearance of epithelial necrosis or sloughing of epithelial cells, were detected in the histology studies.

\section{Acknowledgments}

This work was supported by the Shanghai Medical Key Specialty (grant number ZK2012A26) and the Key Disciplines Group Construction Project of Pudong Health Bureau of Shanghai (grant number PWZxq2014-04).

\section{Disclosure}

The authors report no conflicts of interest in this paper.

\section{References}

1. Parkin DM, Bray F, Ferlay J, Pisani P. Global cancer statistics 2002. CA Cancer J Clin. 2005;55(2):74-108.

2. Khan AS, Fowler KJ, Chapman WC. Current surgical treatment strategies for hepatocellular carcinoma in North America. World J Gastroenterol. 2014;20(41):15007-15017.

3. Sherman M, Colombo M. Hepatocellular carcinoma screening and diagnosis. Semin Liver Dis. 2014;34(4):389-397.

4. O’Suilleabhain CB, Poon RT, Yong JL, Ooi GC, Tso WK, Fan ST. Factors predictive of 5-year survival after transarterial chemoembolization for inoperable hepatocellular carcinoma. Br J Surg. 2003; 90(3):325-331.

5. Burroughs A, Hochhauser D, Meyer T. Systemic treatment and liver transplantation for hepatocellular carcinoma: two ends of the therapeutic spectrum. Lancet Oncol. 2004;5(7):409-418.
6. Bonetti A, Giuliani J, Muggia F. Targeted agents and oxaliplatincontaining regimens for the treatment of colon cancer. Anticancer Res. 2014;34(1):423-434.

7. Thota R, Pauff JM, Berlin JD. Treatment of metastatic pancreatic adenocarcinoma: a review. Oncology (Williston Park). 2014;28(1):70-74.

8. Louafi S, Boige V, Ducreux M, et al. Gemcitabine plus oxaliplatin (GEMOX) in patients with advanced hepatocellular carcinoma (HCC): results of a phase II study. Cancer. 2007;109(7):1384-1390.

9. Yen Y, Lim DW, Chung V, et al. Phase II study of oxaliplatin in patients with unresectable, metastatic, or recurrent hepatocellular cancer: a California Cancer Consortium Trial. Am J Clin Oncol. 2008;31(4): 317-322.

10. Park SB, Lin CS, Krishnan AV, Goldstein D, Friedlander ML, Kiernan MC. Dose effects of oxaliplatin on persistent and transient $\mathrm{Na}+$ conductances and the development of neurotoxicity. PLoS One. 2011;6(4):e18469.

11. Sittl R, Lampert A, Huth T, et al. Anticancer drug oxaliplatin induces acute cooling-aggravated neuropathy via sodium channel subtype $\mathrm{Na}(\mathrm{V}) 1.6-$ resurgent and persistent current. Proc Natl Acad Sci U S A. 2012; 109(17):6704-6709.

12. Chang HI, Yeh MK. Clinical development of liposome-based drugs: formulation, characterization, and therapeutic efficacy. Int J Nanomedicine. 2012;7:49-60.

13. Torchilin VP. Recent advances with liposomes as pharmaceutical carriers. Nat Rev Drug Discov. 2005;4(2):145-160.

14. Allen TM, Cullis PR. Liposomal drug delivery systems: from concept to clinical applications. Adv Drug Deliv Rev. 2013;65(1):36-48.

15. Yang C, Liu HZ, Lu WD, Fu ZX. PEG-liposomal oxaliplatin potentialization of antitumor efficiency in a nude mouse tumor-xenograft model of colorectal carcinoma. Oncol Rep. 2011;25(6):1621-1628.

16. Abu-Lila A, Suzuki T, Doi Y, Ishida T, Kiwada H. Oxaliplatin targeting to angiogenic vessels by PEGylated cationic liposomes suppresses the angiogenesis in a dorsal air sac mouse model. $J$ Control Release. 2009;134(1):18-25.

17. Negishi M, Irie A, Nagata N, Ichikawa A. Specific binding of glycyrrhetinic acid to the rat liver membrane. Biochim Biophys Acta. 1991; 1066(1):77-82.

18. Shiki Y, Shirai K, Saito Y, Yoshida S, Mori Y, Wakashin M. Effect of glycyrrhizin on lysis of hepatocyte membranes induced by anti-liver cell membrane antibody. J Gastroenterol Hepatol. 1992;7(1):12-16.

19. Il'icheva TN, Proniaeva TR, Smetannikov AA, Pokrovskiı̌ AG. [Content of progesterone, glucocorticoid and glycyrrhizic acid receptors in normal and tumoral human breast tissue]. Vopr Onkol. 1998;44(4):390-394. Russian.

20. Tian Q, Zhang CN, Wang XH, et al. Glycyrrhetinic acid-modified chitosan/poly(ethylene glycol) nanoparticles for liver-targeted delivery. Biomaterials. 2010;31(17):4748-4756.

21. Huang W, Wang W, Wang P, et al. Glycyrrhetinic acid-functionalized degradable micelles as liver-targeted drug carrier. J Mater Sci Mater Med. 2011;22(4):853-863.

22. Mao SJ, Bi YQ, Jin H, Wei DP, He R, Hou SX. Preparation, characterization and uptake by primary cultured rat hepatocytes of liposomes surfacemodified with glycyrrhetinic acid. Pharmazie. 2007;62(8):614-619.

23. He ZY, Zheng X, Wu XH, et al. Development of glycyrrhetinic acidmodified stealth cationic liposomes for gene delivery. Int $J$ Pharm. 2010;397(1-2):147-154.

24. Franzen U, Nguyen TT, Vermehren C, Gammelgaard B, Ostergaard J. Characterization of a liposome-based formulation of oxaliplatin using capillary electrophoresis: encapsulation and leakage. J Pharm Biomed Anal. 2011;55(1):16-22.

25. Li J, Xu H, Ke X, Tian J. The anti-tumor performance of docetaxel liposomes surface-modified with glycyrrhetinic acid. J Drug Target. 2012;20(5):467-473.

26. Kim SY, Lee YM. Taxol-loaded block copolymer nanospheres composed of methoxy poly(ethylene glycol) and poly(epsilon-caprolactone) as novel anticancer drug carriers. Biomaterials. 2001;22(13): $1697-1704$. 
27. International Conference on Harmonisation; Stability Data Package for Registration Applications in Climatic Zones III and IV; Stability Testing of New Drug Substances and Products; availability. Notice. Food and Drug Administration, HHS. Fed Regist. 2003;68(225):65717-65718.

28. Chen C, Han D, Cai C, Tang X. An overview of liposome lyophilization and its future potential. J Control Release. 2010;142(3):299-311.

29. Service RF. Nanomaterials show signs of toxicity. Science. 2003; 300(5617):243.
30. Gumpricht E, Dahl R, Devereaux MW, Sokol RJ. Licorice compounds glycyrrhizin and 18beta-glycyrrhetinic acid are potent modulators of bile acid-induced cytotoxicity in rat hepatocytes. $J$ Biol Chem. 2005;280(11):10556-10563.

31. Cheng $\mathrm{M}, \mathrm{Xu} \mathrm{H}$, Wang Y, et al. Glycyrrhetinic acid-modified chitosan nanoparticles enhanced the effect of 5-fluorouracil in murine liver cancer model via regulatory T-cells. Drug Des Devel Ther. 2013;7: 1287-1299.

\section{Publish your work in this journal}

Drug Design, Development and Therapy is an international, peerreviewed open-access journal that spans the spectrum of drug design and development through to clinical applications. Clinical outcomes, patient safety, and programs for the development and effective, safe, and sustained use of medicines are a feature of the journal, which has also been accepted for indexing on PubMed Central. The manuscript management system is completely online and includes a very quick and fair peer-review system, which is all easy to use. Visit http://www.dovepress.com/testimonials.php to read real quotes from published authors.

Submit your manuscript here: http://www.dovepress.com/drug-design-development-and-therapy-journal 